\title{
Trabalhador com deficiência e Previdência Social
}

\section{Disabled worker and social security}

\author{
Alano do Carmo Macêdo ${ }^{a}$ \\ (D) https://orcid.org/0000-0002-3578-9553 \\ Thaynah Barros de Araújob \\ (D) https://orcid.org/0000-0001-7689-3675
}

\begin{abstract}
Resumo: Este texto examina a aposentadoria do trabalhador com deficiência segurado do Regime Geral de Previdência Social. Argumenta-se que a deficiência é resultado de uma produção social da sociabilidade capitalista. As restrições e impactos no reconhecimento do direito são analisados sob o prisma de um país de capitalismo periférico e dependente marcado pela superexploração do trabalho com desestruturação das políticas sociais, mas com possibilidades de luta e resistência da classe trabalhadora.
\end{abstract}

Palavras-chave: Trabalho. Previdência Social. Pessoa com deficiência.

\begin{abstract}
This text examines the retirement of the insured worker of the General Social Security System. It is argued that disability is the result of a social production of capitalist sociability. The restrictions and impacts on the recognition of the right are analyzed from the point of view of a country of peripheral and dependent capitalism marked by the overexploitation of labor with the destructuring of social policies, but with the possibilities of struggle and resistance of the working class.
\end{abstract}

Keywords: Work. Social Security. Disabled person.

\section{Introdução}

s sucessivas crises do capitalismo podem ser explicadas pelas contra-
dições tão caras aos mecanismos que permitem sua existência. Para
Mandel (1990), os processos de (re)produção e recessão são inerentes aos aspectos cíclicos que permeiam os alicerces do sistema capitalista. Assim, impõe-se um conjunto de medidas para reduzir os custos do processo 
produtivo e retomar o lucro, principalmente por meio do desmantelamento de direitos sociais e da superexploração da força de trabalho, obviamente com as devidas particularidades, considerando que somos um país que se insere de forma periférica no capitalismo caracterizado pela dependência. Nesse contexto, a seguridade social brasileira, que abrange um conjunto integrado de ações de iniciativas dos poderes públicos e da sociedade destinado a assegurar os direitos relativos à saúde, à previdência e à assistência social, é alvo da ofensiva neoliberal, o que tem se consolidado em desregulamentações e flexibilizações dos direitos historicamente conquistados.

Nossa contribuição aborda, mais especificamente, a aposentadoria da pessoa com deficiência segurada do Regime Geral de Previdência Social (RGPS), tendo os alicerces no artigo 201 da Constituição Federal de 1988 (CF/1988), contudo, regulamentada somente 25 anos após esta previsão, por meio da Lei Complementar n. 142/2013 (LC n. 142/2013). Pensamos que os critérios cada vez mais restritivos aos benefícios previdenciários mantêm estreita relação com a manutenção do fundo público canalizado para a manutenção da ordem do capital, em uma lógica potencialmente perversa, decorrente dos mecanismos de mundialização (Chesnais, 1996).

Este texto se desdobra, de forma distinta mas correlata, em três pontos fulcrais que se conectam a partir do eixo norteador alicerçado no atual contexto de regressão de direitos, considerando as contrarreformas em curso vinculadas às estratégias do capital para criar contratendências às quedas das taxas de lucro. $O$ debate problematiza elementos estruturais e suas múltiplas expressões na dinâmica da sociedade de classes. Analisamos a deficiência como resultado de uma produção social da sociabilidade capitalista, contrapondo-se às compreensões descontextualizadas do processo saúde, doença e/ou deficiência. Em seguida, abalizamos o conceito de deficiência da Organização das Nações Unidas (ONU) ratificado pelo Brasil e os aspectos jurídico-formais que envolvem o reconhecimento de direito à aposentadoria. Por fim, apontamos dados estatísticos do Instituto Nacional do Seguro Social (INSS) pertinentes ao benefício, reveladores das disputas pelo fundo público e os tensionamentos relacionados à Previdência Social que envolvem interesses de classes antagônicas. 


\section{A produção social da deficiência e a Convenção da ONU}

Ao analisarmos a história, deparamo-nos com as mais diversas problematizações que tratam sobre o conceito de pessoa com deficiência. Nossas pesquisas bibliográficas revelaram a existência de uma dualidade no modo de perceber e/ou conceituar em relação a esses sujeitos. Em uma delas, a deficiência é percebida como manifestação do universo diverso humano, demandando adaptação social para ampliar a acessibilidade dos ambientes às diversidades corporais. No contraponto, a deficiência é relatada como manifestação de restrição corporal, exigindo avanços na área da medicina, da reabilitação e da genética, com o intuito de disponibilizar recursos que melhorem a funcionalidade das funções e estruturas do corpo.

A deficiência observada sob o prisma da desvantagem natural encontra sustentação na biomedicina com uso da intervenção médica para melhorar a condição de vida desses indivíduos. No caso da perspectiva social, pauta a opressão pelo corpo que só é superada quando os espaços sociais se tornam mais acessíveis. Pensamos que, apesar dos avanços no debate desta última, não é suficiente para superar as questões estruturais das desigualdades sociais que perpassam a tessitura da vida dos sujeitos com deficiência, pois é necessário compreender estas a partir do eixo axiológico de exploração do trabalho na sociedade burguesa, principalmente na paradoxal relação entre capitalistas e superexplorados, uma vez que

A história de toda a sociedade até hoje é a história de luta de classes. Homem livre e escravo, patrício e plebeu, barão e servo, burguês da corporação e oficial, em suma, opressores e oprimidos, estiveram em constante antagonismo entre si... [...]. A nossa época, a época da burguesia, distingue-se, contudo, por ter simplificado os antagonismos de classe. Toda a sociedade está a cindir-se, cada vez mais, em dois grandes campos hostis, em duas grandes classes em confronto direto: a burguesia e o proletariado. (Marx e Engels, 2012, p. 35)

Para os movimentos sociais das pessoas com deficiência, a lesão seria uma expressão do corpo, assim como seria o sexo ou mesmo a cor dos cabelos, 
sustentando que o processo estaria diretamente relacionado à opressão e discriminação que os sujeitos sofrem em uma sociedade regida pela lógica do capital que estabelece padrões de normalidade e descarta ou mesmo não prioriza o que for diferente disso. Dessa forma, fica a possibilidade de uma pessoa ser acometida por lesões, mas não vivenciar a deficiência como algo negativo que o deixa em "desvantagem", uma vez que depende da maneira como a sociedade está preparada para conceber essa diferença que não é antítese da igualdade, mas em uma perspectiva que fortalece a construção daquela a partir de identidades individuais e coletivas (Pierucci, 1990).

As investigações censitárias, a partir dos anos 2000, introduziram aspectos específicos para compreender esses sujeitos com deficiência para além das questões patológicas. A pesquisa do Instituto Brasileiro de Geografia e Estatística (IBGE) no ano 2000, apresentou elementos que pautavam os graus de dificuldades enfrentadas diariamente pelas pessoas com lesões, sejam elas relacionadas às habilidades de visão, audição ou locomoção. Assim, em relação aos censos anteriores é possível perceber uma significativa mudança de paradigma. Dados estatísticos do IBGE (2000 e 2010) revelam que no ano 2000, 14,5\% da população possuía alguma deficiência; já em 2010, subiu para 23,9\%, o equivalente a pouco mais de 45 milhões de brasileiros. Embora a estatística de pessoas com deficiência apresente destaque numérico, percebemos que esses sujeitos ainda não atingiram o patamar da garantia e materialização de direitos. Assim,

a deficiência como fenômeno socialmente produzido se alastra e aprofunda as desigualdades sociais pelas desvantagens sociais a que são submetidas as pessoas com deficiência, se não houver intervenção do Estado e da sociedade no sentido de inibir sua produção e reprodução. (CFESS, 2012, p. 2)

A demanda por proteção social está na gênese da elaboração das convenções internacionais específicas para tratar de segmentos com barreiras, como, por exemplo, no acesso aos serviços, sistemas e políticas públicas. No caso do documento pertinente às pessoas com deficiência, foi adotado pela ONU em dezembro de 2006, de acordo com a Resolução n. 61/106 da Assembleia Geral, mas somente entrou em vigor em maio de 2008. No Brasil, essa 
convenção foi aprovada pelo Congresso Nacional com o Decreto Legislativo n. 186/2008. A referida Convenção reconhece a discriminação como violação à dignidade do ser humano (alínea "h") e a importância da autonomia da pessoa com deficiência para fazer suas próprias escolhas (alínea " $n$ ”). Com relação ao conceito de pessoa com deficiência, está explícito no Art. $1^{\circ}$ da convenção, ao definir que

Pessoas com deficiência são aquelas que têm impedimentos de longo prazo de natureza física, mental, intelectual ou sensorial, os quais, em interação com diversas barreiras, podem obstruir sua participação plena e efetiva na sociedade em igualdade de condições com as demais pessoas.

Obviamente que não ocorre negação dos fatores biológicos, mas estes devem ser contextualizados levando em consideração as restrições cotidianas, a exemplo das arquitetônicas e/ou atitudinais que essas pessoas enfrentam na sociedade. Assim, é

perceptível que a deficiência resulta da relação entre pessoas com limitações e as barreiras atitudinais e ambientais que impedem sua participação na sociedade, em igualdade de condições com as demais pessoas. As barreiras assumem relevância e explicitam que a real definição de deficiência está na sociedade, não nos atributos das pessoas que apresentem impedimentos físicos, mentais, intelectuais ou sensoriais. Na medida em que as barreiras culturais, tecnológicas, físicas e de atitudes preconceituosas sejam removidas, as pessoas com impedimentos podem ter uma vida em condições iguais, apesar de possuírem atributos diferentes. A eliminação de barreiras arquitetônicas assegura o direito à mobilidade às pessoas com deficiência física; a criação de meios de comunicação acessíveis permite a livre expressão para os surdos e cegos; métodos apropriados de educação especial propiciam conhecimento às pessoas com deficiência mental e sensorial. (CFESS, 2012, p. 2).

Pensamos que de forma correlata, na esfera social, o desenvolvimento das forças produtivas resulta na reificação e na alienação generalizada das relações humanas. Isso ocorre na medida em que o trabalhador é alienado dos mecanismos de produção e dos produtos do seu trabalho, ou seja, do 
processo produtivo em sua totalidade. Nesse contexto, ele está reduzido a um papel complementar junto a uma máquina que o consome física e mentalmente. (Mandel, 1981).

Como o propósito capitalista é sempre manter a acumulação, ou seja, o lucro em tudo que tem, essa produção termina não tendo um cuidado especial com a condição de saúde dos trabalhadores. Marx (1988, p. 406-407) já sinalizava os reflexos da extenuante jornada de trabalho inglesa associada às péssimas condições laborativas que reverberavam na vida dessas pessoas, conforme relatórios médicos da época.

O dr. Boothroyd, médico prático em Haley, diz: "Cada geração sucessiva de oleiros é mais raquítica e fraca do que a anterior”. Outro médico, o sr. McBean, declara: "Desde que, há 25 anos, comecei a exercer a medicina entre os oleiros, evidenciou-se uma progressiva degeneração dessa classe sob a forma de uma diminuição de estatura e peso".

[...]

O sr. Charles Parsons, até pouco tempo atrás house surgeon [médico-cirurgião] desse mesmo hospital, escreve numa carta ao comissário Longe, entre outras coisas: "Posso falar apenas com base em minhas observações pessoais, e não estatisticamente, mas não hesito em afirmar que minha indignação cresceu cada vez mais ao olhar para essas pobres crianças, cuja saúde foi sacrificada para satisfazer a cupidez de seus pais e de seus empregadores".

Assim, é possível evidenciar a intrínseca relação entre o capitalismo e os intensos processos de saúde-doença que resultam, por vezes, em deficiência, uma vez que "adoecer e acidentar no trabalho são fatores presentes na vida do trabalhador, pois o mote da acumulação capitalista é o uso da força de trabalho pela máquina. Distante está o alívio do trabalhador das atividades árduas" (Lara, 2011, p. 81).

Realizamos pesquisa no banco de teses e dissertações da Coordenação de Aperfeiçoamento de Pessoal de Nível Superior (Capes), donde localizamos quase 90 mil produções acadêmicas com a temática "adoecimento no trabalho", publicadas entre os anos de 1987 e 2017. São pesquisas que referendam o que expusemos, ao revelar a tênue relação entre o processo saúde/doença/ 
deficiência e as atividades laborativas em suas mais diversas expressões no Brasil (saúde, educação, indústria, entre outras) e refletem em sequelas à saúde do trabalhador, na maioria das vezes irreversíveis, que vão desde transtornos mentais a deficiências neuromusculoesqueléticas. Ou seja, a lógica produtiva capitalista também gera deficiência, o que amplia a percepção para além de uma gênese intrinsecamente relacionada ao aspecto congênito, desvelando um perverso sistema que tenta se eximir da responsabilidade de algo que é também gerador. Nesse cenário, torna-se imprescindível o resgate do sentimento de coletividade ou mesmo de pertencimento de classe que encapem lutas sociais contra a ofensiva do capital sobre o trabalho que mutila, adoece, degrada, isola e individualiza o ser social.

\section{Aspectos normativos legais e estruturais da aposentadoria do trabalhador com deficiência}

A Convenção da ONU apresenta um conceito de pessoa com deficiência que não está centrado no indivíduo, ou seja, repugna aquela perspectiva que analisa o sujeito e suas demandas sem perceber estas em interação com as barreiras na sociedade. Em nossas análises, entendemos ser pertinente mediar esse conceito com as possibilidades, os limites e as inflexões, em uma sociabilidade marcada pela descontinuidade, não integralidade, fracionamento e não igualdade de acesso no âmbito das políticas públicas. Assim, é imperativo desvelar essa (des)igualdade burguesa, uma vez que

O processo de universalização da forma mercantil é viabilizado pela igualdade formal que, na sociabilidade do capital, é garantida pelo direito, com base em alguns princípios fundamentais: a igualdade (formal), a propriedade privada e a liberdade de contrato. Dessa forma, o direito aparece como uma estrutura autônoma que sujeita toda a vida social a um sistema de leis e normas, igualando formalmente na esfera fenomênica, na epiderme do real, aquilo que é essencialmente desigual, contraditório e antagônico. (Hillesheim, 2015, p. 134)

No Brasil, há mais de trinta anos, já era competência do Estado legislar sobre a proteção social das pessoas com deficiência, o que fora firmado no 
Art. 24, inciso XIV, da CF/1988. No entanto, no caso específico da Previdência Social, somente por meio da Emenda Constitucional n. 47/2005 ocorrera a previsão de aposentadoria para pessoas com deficiência com critérios diferenciados dos demais segurados do RGPS, regulamentada por meio da LC n. 142/2013. O Decreto n. 8.145/2013 alterou o Regulamento da Previdência Social (RPS), aprovado pelo Decreto n. 3.048/1999, para dispor sobre o benefício ao segurado com deficiência. Assim, nos termos do referido documento:

A concessão da aposentadoria por tempo de contribuição ou por idade ao segurado que tenha reconhecido, em avaliação médica e funcional realizada por perícia própria do INSS, grau de deficiência leve, moderada ou grave, está condicionada à comprovação da condição de pessoa com deficiência na data da entrada do requerimento ou na data da implementação dos requisitos para o benefício.

Nesse sentido, a Portaria Interministerial AGU/MPS/SEDH/MP n. 01, de $27 / 1 / 2014$, estabeleceu nos parágrafos primeiro e segundo do Art. $2^{\circ}$ que

$\S 1^{\circ} \mathrm{A}$ avaliação funcional indicada no caput será realizada com base no conceito de funcionalidade disposto na Classificação Internacional de Funcionalidade, Incapacidade e Saúde - CIF, da Organização Mundial de Saúde, e mediante a aplicação do Índice de Funcionalidade Brasileiro Aplicado para Fins de Aposentadoria - IFBrA, conforme o instrumento anexo a esta Portaria. $\S 2^{\circ} \mathrm{A}$ avaliação médica e funcional, disposta no caput, será realizada pela perícia própria do INSS, a qual engloba a perícia médica e o serviço social, integrantes do seu quadro de servidores públicos. (Grifos nossos)

A construção do instrumento de avaliação da pessoa com deficiência para fins de acesso a esse benefício previdenciário utilizou como ponto de partida o Índice de Funcionalidade Brasileiro (IF-Br), ${ }^{1}$ elaborado pelo

1 Foi desenvolvido por solicitação do governo brasileiro e viabilizado pela Secretaria Nacional de Promoção dos Direitos da Pessoa com Deficiência, considerando a demanda de modelo único de classificação da deficiência para uso em todo o território nacional. Na primeira 
Instituto de Estudos do Trabalho e Sociedade (Iets), em parceria com a Secretaria de Direitos Humanos da Presidência da República, com apoio da Universidade Federal do Rio de Janeiro (UFRJ), o qual define a funcionalidade como eixo central, abrangendo todos os tipos de deficiência. Esse instrumento foi adaptado às exigências da LC n. 142/2013 e passou a ser denominado IF-BrA.

O reconhecimento de direito permite que esse sujeito com deficiência continue exercendo a atividade laborativa habitual sem que o benefício seja cancelado, como seria o caso da aposentadoria por invalidez ou do auxílio-doença. Ao pleitear o benefício por idade, deve-se comprovar um tempo mínimo de quinze anos de contribuição como trabalhador com deficiência por meio da avaliação prevista na LC n. 142/2013. Associado a isso, tem-se a exigência da idade mínima de 60 anos para homens e de 55 anos para mulheres, independentemente do grau de deficiência. Períodos de contribuição sem deficiência e com deficiência podem ser somados, sendo no caso do primeiro feita a devida conversão, conforme as orientações na LC. No caso do benefício por tempo de contribuição, a partir da classificação da deficiência, homens e mulheres deverão preencher quesito mínimo de recolhimentos em anos junto ao INSS, conforme quadro abaixo.

Quadro 1. Relação entre tempo de contribuição e classificação da deficiência

\begin{tabular}{|l|c|c|c|}
\hline & Leve & Moderada & Grave \\
\hline Homem & 33 anos & 29 anos & 25 anos \\
\hline Mulher & 28 anos & 24 anos & 20 anos \\
\hline
\end{tabular}

Fonte: INSS. Elaboração própria.

fase do desenvolvimento do IF-Br, indicadores socioeconômicos de pesquisas do IBGE foram analisados. Também foram realizados grupos focais compostos por pessoas com deficiência, com o objetivo de compreender aspectos pertinentes à funcionalidade para essas pessoas. No segundo momento, o instrumento foi desenvolvido levando-se em conta os resultados da primeira etapa e a opinião de especialistas da área. Na conclusão do processo, foram selecionadas 41 atividades representando sete domínios da funcionalidade (Franzoi et al., 2013). 
Para o instrumental de avaliação médica e funcional, foram selecionadas categorias do componente Atividade e Participação da Classificação Internacional de Funcionalidade, Incapacidade e Saúde (CIF), o que resultou na estruturação do escopo com 41 atividades divididas em sete domínios: sensorial, comunicação, mobilidade, cuidados pessoais, vida doméstica, educação, trabalho e vida econômica, socialização e vida comunitária.

A pontuação do IF-BrA tem como base o modelo de dependência da Medida de Independência Funcional (MIF), ${ }^{2}$ mas não se utiliza dos sete níveis de gradação originais, e sim quatro destes, com o objetivo de facilitar a operacionalização do instrumento. Nesse processo, conforme detalhado no quadro abaixo, são utilizados os seguintes valores: 25, 50, 75 e 100 (quanto menor o valor de classificação, maior é o nível de dependência em relação à atividade realizada).

Quadro 2. Escores utilizados na pontuação do IF-BrA

\begin{tabular}{|c|l|}
\hline Pontuação & \multicolumn{1}{c|}{ Descrição } \\
\hline 25 & $\begin{array}{l}\text { Não realiza a atividade ou é totalmente dependente de terceiros para } \\
\text { realizá-la. Não participa de nenhuma etapa da atividade. }\end{array}$ \\
\hline 50 & $\begin{array}{l}\text { Realiza a atividade com o auxílio de terceiros. O indivíduo participa de } \\
\text { alguma etapa da atividade. Inclui preparo e supervisão. }\end{array}$ \\
\hline 75 & $\begin{array}{l}\text { Realiza a atividade de forma adaptada, sendo necessário algum tipo de } \\
\text { modificação, ou realiza a atividade de forma diferente da habitual ou mais } \\
\text { lentamente. }\end{array}$ \\
\hline 100 & $\begin{array}{l}\text { Realiza a atividade de forma independente, sem nenhum tipo de } \\
\text { adaptação ou modificação, na velocidade habitual e em segurança. }\end{array}$ \\
\hline
\end{tabular}

Fonte: IETS, 2012.

No processo de gradação da deficiência, a pontuação total mínima é de 2.050 e a máxima é de 8.200 , dependendo do que for pontuado por cada

2 Tem como "objetivo primordial o de avaliar de forma quantitativa a carga de cuidados demandada por uma pessoa para a realização de uma série de tarefas motoras e cognitivas de vida diária. Cada uma dessas atividades é avaliada e recebe uma pontuação que parte de 1 (dependência total) a 7 (independência completa) (Riberto et al., 2004). 
profissional em cada uma das 41 atividades, multiplicadas por dois (o que representa o número de profissionais responsáveis envolvidos). A partir da soma das duas avaliações, é possível obter o total de pontos que expressará a classificação da deficiência. Para tanto, estabelece-se as referências no quadro abaixo.

Quadro 3. Parâmetros para classificação da deficiência

\begin{tabular}{|c|c|c|}
\hline $\mathbf{5} .739$ & $\mathbf{2} 5.740$ e $\mathbf{6 . 3 5 4} \leq$ & $\mathbf{2 6 . 3 5 5}$ e $\mathbf{7 . 5 8 4} \leq$ \\
\hline GRAVE & MODERADA & LEVE \\
\hline
\end{tabular}

Fonte: INSS. Elaboração própria.

Os trabalhadores que obtiverem pontuações igual ou acima de 7.585 não vão ter o direito reconhecido, uma vez que esses parâmetros são considerados insuficientes para a concessão do benefício. A avaliação vai fixar, também, a data provável do início da deficiência, bem como registrar possíveis variações no grau ao longo do tempo e estabelecer a duração de respectivos períodos em cada grau, quando for o caso, sendo tal procedimento atribuído ao perito médico.

$\mathrm{Na}$ última etapa, quando pertinente, ocorre a aplicação do método linguístico fuzzy. Utilizam-se três condições que descrevem o grupo de sujeitos que podem apresentar maior comprometimento em relação ao impedimento (auditivo, intelectual - cognitivo e/ou mental, motor e visual): 1) Determinação dos domínios que terão mais peso para cada grupo de funcionalidade; 2) Definição de questões emblemáticas; e 3) Disponibilidade do auxílio de terceiros. No quadro 4 são apontadas as distinções feitas entre os domínios e as perguntas emblemáticas para cada tipo de deficiência. No caso de resposta afirmativa para as condições 2 ou 3, ou havendo pontuação 25 ou 50 em alguma atividade, ou pontuação 75 para todas as atividades dos domínios apontados como relevantes para aquela deficiência, será automaticamente atribuída a menor pontuação identificada em cada um dos domínios relacionados àquele impedimento, alterando a nota conclusiva anterior à aplicação do fuzzy. 
Quadro 4. Condições do método linguístico fuzzy

\begin{tabular}{|c|c|c|c|c|}
\hline & Auditiva & $\begin{array}{c}\text { Intelectual/ } \\
\text { Cognitiva/Mental }\end{array}$ & Motora & Visual \\
\hline Domínios & $\begin{array}{l}\text { Comunicação/ } \\
\text { Socialização }\end{array}$ & $\begin{array}{l}\text { Vida doméstica/ } \\
\text { Socialização }\end{array}$ & $\begin{array}{c}\text { Mobilidade/ } \\
\text { Cuidados } \\
\text { Pessoais }\end{array}$ & $\begin{array}{c}\text { Mobilidade/ } \\
\text { Vida } \\
\text { doméstica }\end{array}$ \\
\hline $\begin{array}{l}\text { Questão } \\
\text { emblemática }\end{array}$ & $\begin{array}{c}\text { A surdez } \\
\text { ocorreu antes } \\
\text { dos } 6 \text { (seis) } \\
\text { anos }\end{array}$ & $\begin{array}{c}\text { Não pode ficar sozinho } \\
\text { em segurança }\end{array}$ & $\begin{array}{c}\text { Desloca-se } \\
\text { exclusivamente } \\
\text { em cadeiras de } \\
\text { rodas }\end{array}$ & $\begin{array}{c}\text { A pessoa já } \\
\text { não enxerga } \\
\text { ao nascer }\end{array}$ \\
\hline
\end{tabular}

Fonte: INSS. Elaboração própria.

Assim, cada uma das 41 atividades é pontuada separadamente, sendo a pontuação de cada domínio atribuída à média das atividades. Por conseguinte, a pontuação total é a média dos sete domínios do instrumental. Assim, tem-se o resultado após aplicação por perito médico e assistente social. Outrossim, o parecer final leva em consideração a aplicação do modelo fuzzy, responsável pela correção da pontuação final, quando aplicado. Deve-se registrar a fragilidade do instrumental que não pontua os fatores ambientais, bem como de abordagens constrangedoras, a exemplo da atividade "relacionamentos íntimos" e outras que contribuem para retomada da perspectiva biomédica como "movimentos finos da mão", "lavar-se", "vestir-se", o que aponta a urgência do debate coletivo e a revisão no processo avaliativo.

\section{A linguagem dos dados estatísticos no Brasil}

O INSS, dada a vasta capilaridade de ação por meio das Agências da Previdência Social (APS), por questões administrativas, está dividido em cinco superintendências regionais: Norte/Centro-Oeste, Nordeste, Sudeste I, Sudeste II e Sul. Estas são responsáveis por gerenciar as unidades nos estados e no Distrito Federal, a partir das Gerências Executivas (GEX) e as APS vinculadas a elas, conforme quadro a seguir. 
Quadro 5. Quantitativos (Superintendência/Estados/Gerências Executivas)

\begin{tabular}{|l|c|c|}
\hline \multicolumn{1}{|c|}{ Superintendência } & Estado (mais o Distrito Federal) & Gerências \\
\hline Norte/Centro-Oeste & AC, AM, AP, DF, GO, MT, MS, PA, RO, RR, TO & 17 \\
\hline Nordeste & AL, BA, CE, MA, PE, PB, PI, RN, SE & 23 \\
\hline Sudeste I & SP & 23 \\
\hline Sudeste II & ES, MG, RJ & 22 \\
\hline Sul & PR, RS, SC & 19 \\
\hline Total & $\mathbf{2 7}$ & $\mathbf{1 0 4}$ \\
\hline
\end{tabular}

Fonte: INSS. Elaboração própria.

Dos dados obtidos do INSS, por meio da Lei n. 12.527/2011, elaboramos os quadros a seguir com o quantitativo de requerimentos no Brasil entre 2015 e 2017. É oportuno registrar que fora solicitado acesso às estatísticas desde a operacionalização do benefício no ano de 2014, no entanto, foi-nos informado que a depuração dos sistemas operacionais de dados relativos ao benefício somente fora adequada para extração do Sistema Único de Benefícios (SUB) posterior ao início da concessão das aposentadorias da LC n. 142/2013, o que justifica a ausência dos elementos a partir do ano de 2014. Registre-se que os dados estatísticos estão em valores aproximados com o intuito de facilitar as comparações descritas no decorrer do texto.

Esses dados apontam a Gerência Executiva Recife com a demanda mais elevada, ainda que as unidades de atendimentos vinculadas às Gerências Executivas em Fortaleza e em Salvador apresentem volume bem próximo de requerimentos aos registrados no Recife. Já a Gerência Executiva Barreiras apresentou o menor quantitativo para o período considerado, quando comparado às outras unidades administrativas do INSS na região Nordeste, onde também identificamos que 100\% dos benefícios protocolados na referida unidade foram indeferidos. Nas demais Gerências Executivas observamos que o percentual de benefícios concedidos entre 2015 e 2017 variou de 4\% a 20\%, sendo estas taxas identificadas, respectivamente, nas unidades administrativas em Itabuna e Fortaleza. Assim, a capital cearense figura com uma das maiores demandas da 
Quadro 6. Quantitativos de requerimentos, deferimentos e indeferimentos da aposentadoria da pessoa com deficiência na Superintendência Regional Nordeste

\begin{tabular}{|c|c|c|c|c|c|c|c|c|c|}
\hline \multicolumn{10}{|c|}{ Superintendência Regional Nordeste } \\
\hline \multirow{2}{*}{$\begin{array}{l}\text { Gerência } \\
\text { Executiva }\end{array}$} & \multicolumn{3}{|c|}{2015} & \multicolumn{3}{|c|}{2016} & \multicolumn{3}{|c|}{2017} \\
\hline & $\mathbf{R}$ & D & I & $\mathbf{R}$ & D & I & $\mathbf{R}$ & D & 1 \\
\hline Aracaju & 114 & 5 & 109 & 79 & 5 & 74 & 86 & 10 & 76 \\
\hline Barreiras & 5 & - & 5 & 9 & - & 9 & 9 & - & 9 \\
\hline Campina Grande & 53 & 1 & 52 & 71 & 8 & 63 & 61 & 6 & 55 \\
\hline Caruaru & 91 & 2 & 89 & 38 & 3 & 35 & 33 & 6 & 27 \\
\hline Feira de Santana & 63 & 4 & 59 & 53 & 4 & 49 & 82 & 6 & 76 \\
\hline Fortaleza & 328 & 47 & 281 & 236 & 62 & 174 & 352 & 63 & 289 \\
\hline Garanhuns & 48 & 1 & 47 & 20 & 2 & 18 & 12 & 2 & 10 \\
\hline Imperatriz & 27 & 3 & 24 & 22 & 2 & 20 & 34 & - & 34 \\
\hline Itabuna & 75 & 2 & 73 & 43 & 6 & 37 & 63 & 1 & 62 \\
\hline João Pessoa & 112 & 5 & 107 & 150 & 9 & 141 & 156 & 14 & 142 \\
\hline Juazeiro & 50 & 3 & 47 & 50 & 5 & 45 & 54 & 5 & 49 \\
\hline Juazeiro do Norte & 30 & - & 30 & 40 & 6 & 34 & 28 & 4 & 24 \\
\hline Maceió & 150 & 3 & 147 & 193 & 9 & 184 & 233 & 12 & 221 \\
\hline Mossoró & 49 & 2 & 47 & 34 & 9 & 25 & 15 & 4 & 11 \\
\hline Natal & 138 & 3 & 135 & 62 & 5 & 57 & 54 & 9 & 45 \\
\hline Petrolina & 21 & 1 & 20 & 31 & 4 & 27 & 36 & 3 & 33 \\
\hline Recife & 358 & 20 & 338 & 276 & 29 & 247 & 289 & 26 & 263 \\
\hline Salvador & 284 & 24 & 260 & 267 & 31 & 236 & 350 & 31 & 319 \\
\hline $\begin{array}{l}\text { Santo Antônio de } \\
\text { Jesus }\end{array}$ & 44 & 1 & 43 & 25 & 2 & 23 & 39 & 1 & 38 \\
\hline São Luís & 92 & 3 & 89 & 77 & 3 & 74 & 102 & 8 & 94 \\
\hline Sobral & 32 & - & 32 & 23 & 2 & 21 & 22 & 2 & 20 \\
\hline Teresina & 87 & 4 & 83 & 111 & 8 & 103 & 109 & 7 & 102 \\
\hline Vitória da Conquista & 39 & 3 & 36 & 54 & 5 & 49 & 44 & 6 & 38 \\
\hline Total & 2.290 & 137 & 2.153 & 1.964 & 218 & 1.746 & 2.263 & 226 & 2.037 \\
\hline
\end{tabular}

R: requerimento; D: deferimento; I: indeferimento.

Fonte: Sistema Único de Informações de Benefícios (Suibe)/INSS. Elaboração própria. 
Superintendência Regional Nordeste e com o melhor índice de deferimento de benefício para o período analisado.

Quadro 7. Quantitativos de requerimentos, deferimentos e indeferimentos da aposentadoria da pessoa com deficiência na Superintendência Norte/Centro-Oeste

\begin{tabular}{|c|c|c|c|c|c|c|c|c|c|}
\hline \multicolumn{10}{|c|}{ Superintendência Regional Norte/Centro-Oeste } \\
\hline \multirow{2}{*}{$\begin{array}{l}\text { Gerência } \\
\text { Executiva }\end{array}$} & \multicolumn{3}{|c|}{2015} & \multicolumn{3}{|c|}{2016} & \multicolumn{3}{|c|}{2017} \\
\hline & $\mathbf{R}$ & D & 1 & $\mathbf{R}$ & D & 1 & $\mathbf{R}$ & D & I \\
\hline Anápolis & 70 & 3 & 67 & 96 & 5 & 91 & 100 & 5 & 95 \\
\hline Belém & 215 & 2 & 213 & 107 & 5 & 102 & 117 & 12 & 105 \\
\hline Boa Vista & 8 & 1 & 7 & 11 & 1 & 10 & 22 & 1 & 21 \\
\hline Campo Grande & 98 & 10 & 88 & 94 & 14 & 80 & 161 & 7 & 154 \\
\hline Cuiabá & 85 & 7 & 78 & 153 & 7 & 146 & 173 & 10 & 163 \\
\hline Distrito Federal & 305 & 45 & 260 & 385 & 61 & 324 & 520 & 56 & 464 \\
\hline Dourados & 44 & - & 44 & 60 & 4 & 56 & 37 & 3 & 34 \\
\hline Goiânia & 197 & 28 & 169 & 188 & 32 & 156 & 322 & 47 & 275 \\
\hline Macapá & 16 & - & 16 & 9 & 1 & 8 & 9 & 1 & 8 \\
\hline Marabá & 29 & - & 29 & 10 & - & 10 & 20 & 1 & 19 \\
\hline Manaus & 184 & 6 & 178 & 157 & 9 & 148 & 219 & 15 & 204 \\
\hline Palmas & 31 & 2 & 29 & 41 & 4 & 37 & 50 & 4 & 46 \\
\hline Porto Velho & 26 & 1 & 25 & 40 & 1 & 39 & 47 & 1 & 46 \\
\hline Rio Branco & 14 & - & 14 & 22 & 1 & 21 & 20 & 1 & 19 \\
\hline Santarém & 11 & - & 11 & 11 & - & 11 & 14 & 2 & 12 \\
\hline Sinop & 11 & - & 11 & 19 & 1 & 18 & 14 & - & 14 \\
\hline Tefé & 1 & - & 1 & 5 & - & 5 & 3 & - & 3 \\
\hline Total & 1.345 & 105 & 1.240 & 1.408 & 148 & 1.260 & 1.848 & 164 & 1.684 \\
\hline
\end{tabular}

R: requerimento; D: deferimento; I: indeferimento.

Fonte: Sistema Único de Informações de Benefícios (Suibe)/INSS. Elaboração própria.

Dos dados acima, podemos extrair que a Gerência Executiva no Distrito Federal é responsável pela maior demanda dentre as unidades vinculadas à Superintendência Regional Norte/Centro-Oeste e aquela com menor quantidade ficou com a Gerência Executiva Tefé, tendo nesta última o pior índice de indeferimento do benefício, com 100\% dos pedidos negados. Com relação às taxas de concessão nas demais unidades do INSS para o 
período considerado, identificamos que Marabá registrou taxa inferior a $2 \%$, enquanto Goiânia apresentou o melhor índice de deferimento, com o percentual aproximado de $15 \%$.

Quadro 8. Quantitativos de requerimentos, deferimentos e indeferimentos da aposentadoria da pessoa com deficiência na Superintendência Regional Sudeste I

\begin{tabular}{|c|c|c|c|c|c|c|c|c|c|}
\hline \multicolumn{10}{|c|}{ Superintendência Regional Sudeste I } \\
\hline \multirow{2}{*}{$\begin{array}{l}\text { Gerência } \\
\text { Executiva }\end{array}$} & \multicolumn{3}{|c|}{2015} & \multicolumn{3}{|c|}{2016} & \multicolumn{3}{|c|}{2017} \\
\hline & $\mathbf{R}$ & D & 1 & $\mathbf{R}$ & D & 1 & $\mathbf{R}$ & D & I \\
\hline Araçatuba & 74 & 13 & 61 & 118 & 23 & 95 & 141 & 30 & 111 \\
\hline Araraquara & 151 & 23 & 128 & 137 & 24 & 113 & 227 & 38 & 189 \\
\hline Bauru & 149 & 27 & 122 & 207 & 29 & 178 & 227 & 43 & 184 \\
\hline Campinas & 239 & 29 & 210 & 338 & 61 & 277 & 469 & 71 & 398 \\
\hline Guarulhos & 347 & 35 & 312 & 290 & 30 & 260 & 700 & 34 & 666 \\
\hline Jundiaí & 171 & 33 & 138 & 202 & 44 & 158 & 273 & 41 & 232 \\
\hline Marília & 106 & 8 & 98 & 176 & 32 & 144 & 161 & 22 & 139 \\
\hline Osasco & 141 & 8 & 133 & 111 & 18 & 93 & 195 & 10 & 185 \\
\hline Piracicaba & 135 & 24 & 111 & 154 & 31 & 123 & 266 & 65 & 201 \\
\hline Presidente Prudente & 60 & 12 & 48 & 97 & 16 & 81 & 80 & 11 & 69 \\
\hline Ribeirão Preto & 167 & 34 & 133 & 262 & 45 & 217 & 383 & 40 & 343 \\
\hline Santo André & 379 & 35 & 344 & 395 & 53 & 342 & 436 & 51 & 385 \\
\hline Santos & 230 & 14 & 216 & 207 & 18 & 189 & 212 & 22 & 190 \\
\hline São B. do Campo & 316 & 56 & 260 & 647 & 200 & 447 & 1296 & 322 & 974 \\
\hline São João da Boa Vista & 136 & 30 & 106 & 186 & 30 & 156 & 199 & 38 & 161 \\
\hline São José do Rio Preto & 267 & 32 & 235 & 264 & 27 & 237 & 258 & 25 & 233 \\
\hline São José dos Campos & 140 & 19 & 121 & 135 & 10 & 125 & 134 & 14 & 120 \\
\hline São Paulo - Centro & 359 & 57 & 302 & 513 & 82 & 431 & 684 & 153 & 531 \\
\hline São Paulo - Norte & 311 & 49 & 262 & 293 & 38 & 255 & 454 & 74 & 380 \\
\hline São Paulo - Sul & 1.024 & 127 & 897 & 1.239 & 194 & 1.045 & 1.338 & 188 & 1.150 \\
\hline São Paulo - Leste & 678 & 65 & 613 & 626 & 115 & 511 & 662 & 110 & 552 \\
\hline Sorocaba & 286 & 37 & 249 & 235 & 55 & 180 & 418 & 64 & 354 \\
\hline Taubaté & 116 & 15 & 101 & 111 & 12 & 99 & 202 & 28 & 174 \\
\hline Total & 5.982 & 782 & 5.200 & 6.943 & 1.187 & 5.756 & 9.415 & 1.494 & 7.921 \\
\hline
\end{tabular}

R: requerimento; D: deferimento; I: indeferimento.

Fonte: Sistema Único de Informações de Benefícios (Suibe)/INSS. Elaboração própria. 
Dos dados apresentados no quadro 8, identificamos que a demanda mais expressiva em termos numéricos está na Gerência Executiva São Paulo - Sul e aquela com menor quantitativo de requerimentos protocolados é a unidade administrativa do INSS em Presidente Prudente. No período considerado, a menor taxa de concessão do benefício ocorreu em Guarulhos, com aproximadamente 7,5\% dos pedidos deferidos. Já na Gerência Executiva São Bernardo do Campo, com a segunda maior demanda de benefícios requeridos do estado de São Paulo, foi registrado aproximadamente um índice de $25 \%$ de pareceres favoráveis, sendo o melhor índice desta superintendência.

Identificamos no quadro 9 que a demanda mais elevada do benefício está concentrada na Gerência Executiva Rio de Janeiro - Centro e a menor na unidade administrativa do INSS em Diamantina. Com relação ao quantitativo de benefícios concedidos, o melhor índice em termos de pareceres favoráveis é da Rio de Janeiro - Centro, com aproximadamente $22 \%$, enquanto Teófilo Otoni tem o menor percentual de concessão, que ficou em torno de $5 \%$ de deferimentos.

Os dados do quadro 10 revelam que a Gerência Executiva com maior demanda é localizada na capital paranaense, e a unidade gerencial do INSS com um menor número de requerimentos protocolados é a situada na cidade de Uruguaiana e que também apresenta o mais baixo índice de concessão com apenas 7\%, enquanto a Gerência Executiva Caxias do Sul tem 25\% de deferimentos.

Pensamos que as desigualdades expressas nessas informações estatísticas não devem ser analisadas como problemas de determinada região, mas conectada à dinâmica de um país capitalista periférico que prima pela manutenção dos vínculos de dependência e acirra as desigualdades sociais, econômicas e políticas, sendo possível depreender que o desenvolvimento não é avaliado na perspectiva de uma ação histórica com etapas definidas, mas, conforme Fernandes (2006), deve-se compreender a partir da intrínseca relação entre dependência e (sub)desenvolvimento, que integram uma estratégia relacionada ao modo de produção capitalista que concretiza de forma desigual e combinada a manutenção da propriedade privada e 
Quadro 9. Quantitativos de requerimentos, deferimentos e indeferimentos da aposentadoria da pessoa com deficiência na Superintendência Regional Sudeste II

\begin{tabular}{|c|c|c|c|c|c|c|c|c|c|}
\hline \multicolumn{10}{|c|}{ Superintendência Regional Sudeste II } \\
\hline \multirow{2}{*}{$\begin{array}{l}\text { Gerência } \\
\text { Executiva }\end{array}$} & \multicolumn{3}{|c|}{2015} & \multicolumn{3}{|c|}{2016} & \multicolumn{3}{|c|}{2017} \\
\hline & $\mathbf{R}$ & D & 1 & $\mathbf{R}$ & D & I & $\mathbf{R}$ & D & I \\
\hline Barbacena & 86 & 14 & 72 & 139 & 26 & 113 & 122 & 29 & 93 \\
\hline Belo Horizonte & 430 & 71 & 359 & 549 & 91 & 458 & 600 & 92 & 508 \\
\hline Campos & 85 & 7 & 78 & 112 & 6 & 106 & 105 & 11 & 94 \\
\hline Contagem & 245 & 21 & 224 & 270 & 35 & 235 & 252 & 33 & 219 \\
\hline Diamantina & 23 & 3 & 20 & 29 & 2 & 27 & 32 & 6 & 26 \\
\hline Divinópolis & 175 & 23 & 152 & 194 & 38 & 156 & 217 & 37 & 180 \\
\hline Duque de Caxias & 264 & 20 & 244 & 260 & 11 & 249 & 373 & 22 & 351 \\
\hline Juiz de Fora & 112 & 16 & 96 & 106 & 26 & 80 & 118 & 18 & 100 \\
\hline Montes Claros & 50 & 6 & 44 & 72 & 3 & 69 & 72 & 4 & 68 \\
\hline Niterói & 189 & 25 & 164 & 210 & 17 & 193 & 257 & 26 & 231 \\
\hline Ouro Preto & 105 & 7 & 98 & 147 & 10 & 137 & 150 & 11 & 139 \\
\hline Petrópolis & 102 & 17 & 85 & 119 & 22 & 97 & 124 & 23 & 101 \\
\hline Poços de Caldas & 121 & 26 & 95 & 128 & 19 & 109 & 150 & 24 & 126 \\
\hline $\begin{array}{l}\text { Rio de Janeiro - } \\
\text { Centro }\end{array}$ & 541 & 141 & 400 & 609 & 147 & 462 & 642 & 107 & 535 \\
\hline $\begin{array}{l}\text { Rio de Janeiro - } \\
\text { Norte }\end{array}$ & 278 & 27 & 251 & 208 & 26 & 182 & 307 & 33 & 274 \\
\hline Teófilo Otoni & 33 & - & 33 & 39 & 2 & 37 & 26 & 3 & 23 \\
\hline Uberaba & 70 & 9 & 61 & 95 & 18 & 77 & 76 & 16 & 60 \\
\hline Uberlândia & 104 & 18 & 86 & 105 & 18 & 87 & 143 & 33 & 110 \\
\hline Varginha & 93 & 1 & 92 & 120 & 7 & 113 & 111 & 11 & 100 \\
\hline Vitória & 256 & 36 & 220 & 371 & 52 & 319 & 394 & 39 & 355 \\
\hline Volta Redonda & 127 & 11 & 116 & 136 & 24 & 112 & 168 & 21 & 147 \\
\hline Total & 3.619 & 514 & 3.105 & 4.146 & 623 & 3.523 & 4.613 & 646 & 3.967 \\
\hline
\end{tabular}

R: requerimento; D: deferimento; I: indeferimento.

Fonte: Sistema Único de Informações de Benefícios (Suibe)/INSS. Elaboração própria. 
Quadro 10. Quantitativos de requerimentos, deferimentos e indeferimentos da aposentadoria da pessoa com deficiência na Superintendência Regional Sul

\begin{tabular}{|c|c|c|c|c|c|c|c|c|c|}
\hline \multicolumn{10}{|c|}{ Superintendência Regional Sul } \\
\hline \multirow{2}{*}{$\begin{array}{l}\text { Gerência } \\
\text { Executiva }\end{array}$} & \multicolumn{3}{|c|}{2015} & \multicolumn{3}{|c|}{2016} & \multicolumn{3}{|c|}{2017} \\
\hline & $\mathbf{R}$ & D & 1 & $\mathbf{R}$ & D & I & $\mathbf{R}$ & D & I \\
\hline Blumenau & 260 & 35 & 225 & 324 & 56 & 268 & 524 & 81 & 443 \\
\hline Canoas & 134 & 15 & 119 & 124 & 24 & 100 & 157 & 15 & 142 \\
\hline Cascavel & 159 & 26 & 133 & 154 & 33 & 121 & 202 & 31 & 171 \\
\hline Chapecó & 153 & 23 & 130 & 209 & 34 & 175 & 290 & 37 & 253 \\
\hline Caxias do Sul & 151 & 36 & 115 & 181 & 59 & 122 & 371 & 85 & 286 \\
\hline Curitiba & 413 & 51 & 362 & 371 & 71 & 300 & 530 & 68 & 462 \\
\hline Criciúma & 112 & 19 & 93 & 115 & 21 & 94 & 160 & 39 & 121 \\
\hline Florianópolis & 106 & 11 & 95 & 142 & 19 & 123 & 136 & 25 & 111 \\
\hline Ijuí & 66 & 7 & 59 & 70 & 16 & 54 & 108 & 9 & 99 \\
\hline Joinville & 150 & 25 & 125 & 211 & 31 & 180 & 256 & 48 & 208 \\
\hline Londrina & 139 & 16 & 123 & 161 & 25 & 136 & 291 & 37 & 254 \\
\hline Maringá & 129 & 17 & 112 & 147 & 45 & 102 & 152 & 29 & 123 \\
\hline Novo Hamburgo & 178 & 21 & 157 & 189 & 17 & 172 & 184 & 24 & 160 \\
\hline Passo Fundo & 65 & 6 & 59 & 83 & 9 & 74 & 104 & 12 & 92 \\
\hline Pelotas & 83 & 4 & 79 & 95 & 11 & 84 & 91 & 8 & 83 \\
\hline Ponta Grossa & 108 & 12 & 96 & 109 & 16 & 93 & 144 & 7 & 137 \\
\hline Porto Alegre & 256 & 25 & 231 & 252 & 41 & 211 & 332 & 33 & 299 \\
\hline Santa Maria & 69 & 11 & 58 & 95 & 13 & 82 & 118 & 21 & 97 \\
\hline Uruguaiana & 31 & 3 & 28 & 31 & 1 & 30 & 45 & 3 & 42 \\
\hline Total & 2.762 & 363 & 2.399 & 3.063 & 542 & 2.521 & 4.123 & 612 & 3.511 \\
\hline
\end{tabular}

R: requerimento; D: deferimento; I: indeferimento.

Fonte: Sistema Único de Informações de Benefícios (Suibe)/INSS. Elaboração própria.

a intensa precarização das condições de trabalho, sendo possível, nesse sentido, interpretar que

A situação de dependência e subordinação orgânica e funcional da economia brasileira com relação ao conjunto internacional de que participa é um fato que se prende às raízes da formação do país [...]. Essa é a circunstância principal 
que tornará o Brasil tão vulnerável à penetração do capital financeiro internacional quando o capitalismo chega a essa fase de seu desenvolvimento. 0 país se fará imediata e como que automaticamente, sem resistência alguma, em fácil campo para suas operações. (Prado Jr., 2014, p. 116)

Em nossas análises, é nessa perversa conjuntura de intensas contrarreformas que se expressam os dilemas da aposentadoria do trabalhador com deficiência. Os dados no cenário brasileiro, podem ser reveladores da heterogeneidade de concepções dos profissionais associadas não só, mas também, aos aspectos restritivos do instrumental, uma vez que as estatísticas de concessão são consideravelmente inferiores àquelas que negaram o benefício. Quando realizado comparativo entre as gerências, é possível observar que existem unidades do INSS que apresentam índices de indeferimentos superiores a outras, o que sugere estudos futuros para refletir sobre as especificidades regionais e locais dessa perversa alquimia que pauta o reconhecimento de direito ao trabalhador com deficiência.

\section{Conclusão}

Como nossa proposta não era de esgotar este debate, mas de contribuir com elementos que pudessem adensá-lo, pensamos que existem aspectos com demanda de investigação em cada superintendência regional, por conseguinte no âmbito das gerências executivas e das agências, principalmente das influências da formação sócio-histórica regional e seus aspectos estruturais associadas a questões teórico-metodológicas dos profissionais envolvidos e, por fim, a estruturação do instrumento. É possível que (co) existam, tanto no Serviço Social como na Perícia Médica, concepções que transitam na perspectiva biomédica ou na direção da tese social, o que pode explicar as diferentes taxas de concessão/indeferimento quando utilizado um mesmo instrumental. Esses aspectos não anulam a necessidade de debater o instrumento e os parâmetros norteadores junto aos movimentos sociais das pessoas com deficiência, bem como envolver os profissionais que realizam, cotidianamente, as avaliações, uma vez que esse importante momento não ocorreu na construção do atual instrumento. 
Diante desses ataques aos direitos conquistados, pensamos que a classe trabalhadora nas economias de capitalismo periférico e dependente tem importante atuação, enquanto sujeitos históricos, nos tensionamentos para socialização da riqueza coletivamente produzida, ainda que a burguesia, sob o aval do Estado criminalista e militarista, elabore mecanismos de interferência nas condições objetivas e subjetivas em uma perspectiva repressora da organização política desses trabalhadores na luta por direitos na sociabilidade sob a égide do capital que reverberam, principalmente, pela via da (des)estruturação das legislações trabalhistas e previdenciárias, o que se agudiza no cenário brasileiro em tempos de governo imbecilizado com a ofensiva conservadora que visa comprimir as mais diversas formas de resistência.

\section{Referências}

CENSO DEMOGRÁFICO 2010. Características gerais da população, religião e pessoas com deficiência. Rio de Janeiro: IBGE, 2012. Disponível em: <ftp://ftp.ibge.gov.br/Censos/ Censo_Demografico_2010/Caracteristicas_Gerais_Religiao_Deficiencia/caracteristicas_religiao_deficiencia.pdf $>$. Acesso em: 8 mar. 2018.

CHESNAIS, François. A mundialização do capital. Tradução: Silvana Finzi Foá. São Paulo: Xamã, 1996.

CONSELHO FEDERAL DE SERVIÇO SOCIAL. 3a Conferência Nacional dos Direitos da Pessoa com Deficiência e Dia Internacional da Pessoa com Deficiência. Dez. 2012. Disponível em: <http://www.cfess.org.br/arquivos/cfessmanifesta2012_pessoacomdeficienciaFINAL. pdf $>$. Acesso em: 7 mar. 2018.

FERNANDES, Florestan. A revolução burguesa no Brasil: ensaio de interpretação sociológica. Rio de Janeiro: Biblioteca Azul, 2006.

FRANZOI, Ana Cristina et al. Etapas da elaboração do Instrumento de Classificação do Grau de Funcionalidade de Pessoas com Deficiência para Cidadãos Brasileiros: Índice de Funcionalidade Brasileiro - IF-Br. Acta Fisiátrica, São Paulo, v. 20, n. 3, p. 164-178, 2013.

HILLESHEIM, Jaime. Conciliação trabalhista: ofensiva sobre os direitos dos trabalhadores na periferia do capitalismo. 2015. 695 f. Tese (Doutorado em Serviço Social) - Centro Socioeconômico da UFSC. Universidade Federal de Santa Catarina, Florianópolis, 2015.

INSTITUTO DE ESTUDOS DO TRABALHO E SOCIEDADE (IETS). Manual do Índice de Funcionalidade Brasileiro (IF-Br): Elaboração de Instrumento de Classificação do Grau de Funcionalidade de Pessoas com Deficiência para Cidadãos Brasileiros. Disponível em: <http://www.actafisiatrica.org.br/imagebank/pdf/Manual_do_IF-Br.pdf >. Acesso em: 20 jun. 2018. 
LARA, Ricardo. Saúde do trabalhador: considerações a partir da crítica da economia política. Revista Katálysis, Florianópolis, v. 14, n. 1, p. 78-85, jan./jun. 2011.

MANDEL, Ernest. A crise do capital: os fatos e sua interpretação marxista. São Paulo: Ensaio, 1990.

Marxismo revolucionário atual. Rio de Janeiro: Zahar, 1981.

MARX, Karl. $O$ capital. Livro 1. Volume I. Tradução: Reginaldo Sant'Anna. 12a ed. Rio de Janeiro: Bertrand Brasil S. A., 1988.

MARX, Karl; ENGELS, Friedrich. Manifesto do Partido Comunista. Tradução: Sérgio Tellaroni. Rio de Janeiro: Companhia das Letras, 2012.

PRADO JR., Caio. A revolução brasileira: a questão agrária no Brasil. São Paulo: Companhia das Letras, 2014.

PIERUCCI, Antônio Flávio. Ciladas da diferença. Revista Tempo Social, São Paulo, v. II, n. II, p. 7-33, jul./dez. 1990.

RIBERTO, Marcelo et al. Validação da Versão Brasileira da Medida de Independência Funcional. Acta Fisiátrica, São Paulo, v. 11, n. 2, p. 72-76, 2004.

\section{Sobre os autores}

Alano do CARMo MacÊDo - Assistente social. Doutor em Serviço Social. E-mail: alanomacedo@yahoo.com.br

Thaynah Barros de Araújo - Assistente social; docente; mestra em Avaliação de Políticas Públicas.

E-mail: thaynahba@gmail.com 